\title{
SOBRE A RAZÃO DE ESTADO CLÁSSICA E SEUS ESTUDOS RECENTES
}

\author{
FOR REASONS OF STATE: THE CLASSIC NOTION AND RECENT STUDIES
}

\author{
EUGÊNIO MATTIOLI GONÇALVES ${ }^{1}$ \\ Universidade de São Paulo (USP) - Brasil \\ emgoncalves@usp.br
}

\begin{abstract}
RESUMO: Problema clássico da filosofia política, a razão de Estado trata do uso da derroga por parte do governante, em vista da segurança e conservação do Estado. Essa questão - é legítimo ao príncipe descumprir as leis por um bem maior? - remonta à antiguidade, mas encontra seu ápice nos séculos XVI e XVII, acompanhando o nascimento da nova estrutura estatal de poder. Nesse período, o maquiavelismo e suas práticas dão o tom do debate, refletido nos gabinetes políticos da época, solo do absolutismo europeu. A maior parte dos estudos sobre esse tema se concentra na Europa, na segunda metade do século XX, formando a base de comentários para os trabalhos contemporâneos sobre a razão de Estado moderna. As contribuições brasileiras, porém, são raras. O intuito deste artigo, portanto, é duplo: expor, brevemente, o percurso que caracteriza a formulação do conceito, e posteriormente apresentar os principais estudos recentes sobre o assunto, procurando enriquecer o debate brasileiro.
\end{abstract}

PALAVRAS-CHAVE: Razão de Estado. Maquiavelismo. Raison d'État. Nicolau Maquiavel. Prudência política.

\begin{abstract}
A classic problem of the history of political philosophy, reasons of State, refers to the use of derogation by the ruler in order to preserve security and the State itself. Such an issue whether it ever be legitimate for the Prince to disobey the law for a greater good - can be traced back to antiquity, with its climax in the $16^{\text {th }}$ and $17^{\text {th }}$ centuries, when a new state structure of power was emerging. Back then, Machiavelianism, and its practice, set the debate, as reflected in the political offices of the period, the birthplace of European absolutism. Most studies of this subject are concentrated on Europe, in the second half of the $20^{\text {th }}$ century, this attracting the bulk of commentators on contemporary works on the modern approach to reasons of State. Brazilian contributions, however, are scarce. The purpose of this article, therefore, is twofold: to briefly present the constitution of this concept and then to expose the main recent studies on this topic, seeking to enrich debates in Brazil.
\end{abstract}

KEYWORDS: Reason of State. Machiavelianism. Raison d'État. Niccolo Machiavelli. Political prudence.

\section{BREVE hISTÓRIA DA RAZÃo dE ESTADO}

Até hoje, tentar encontrar a origem da ideia de razão de Estado é uma questão que gera controvérsia. Quanto ao termo em si, a maioria dos comentadores parece concordar em que o primeiro a utilizá-lo no intuito de descrevê-la teria sido

\footnotetext{
${ }^{1}$ Doutorando em Filosofia na Universidade de São Paulo (USP).
} 
Giovanni Della Casa, em seu Orazione a Carlo V, de $1550 .^{2}$ Rodolfo De Mattei, entretanto, aponta que no diálogo Del Reggimento di Firenze, composto por Guicciardini entre 1521 e 1523, um dos interlocutores se refere à "ragione degli Stati”" (DE MATTEI, 1979, p. 1). Não surpreende, pois, que pouco profícua pareça a discussão sobre a nomeação primeira do conceito; a afirmação de Etienne Thuau sobre a presença do vocabulário estadista na França do começo do século XVII se aplica também - ainda que em menor medida - à Itália do XVI:

O impulso estatizante é perceptível na linguagem da época, e é possível observar uma inflação [no uso] de expressões onde entra a palavra "Estado". [...] nos deparamos com "escrúpulos de Estado", "considerações de Estado", "quimeras de Estado", "crimes de Estado" e "imprudências de Estado". Nessas expressões, o qualificativo "de Estado" é equivalente a "política", e assume portanto o sentido próprio de "que diz respeito à coletividade racionalmente organizada ou ao aparelho de direção" [...]. Mas dessas expressões, as que ocorrem mais freqüentemente são "razão de Estado", "golpe de Estado", "necessidade de Estado" e "mistério de Estado" (THUAU, 2000, p. 394-395). ${ }^{3}$

Aqui, por razão de Estado, começa a ser esboçada a concepção de uma razão política, uma urgência de grau superior que o príncipe deve realizar necessária por se vincular à proteção do governo e de seu próprio poder, e por isso elevada a uma instância maior -, que justificaria o uso da dissimulação ou outras ações anteriormente injustificáveis.

É claro que essa temática não é inédita na história da filosofia. Do discurso ciceroniano do útil e do honesto à derroga em Tomás de Aquino, ${ }^{4}$ a discussão sobre a justiça ou tirania de um governante a partir de suas ações no poder remete à República de Platão. ${ }^{5}$ Mas é somente no solo desse Renascimento europeu, num retorno aos antigos que passa a cultivar novamente a esfera política, que brota o debate sobre os Estados e as razões que deveriam [ou não] guiá-los. ${ }^{6}$

\footnotetext{
${ }^{2}$ Benedetto Croce aponta que o primeiro a indicar essa referência seria Scipione Chiaramonte, no tratado Della Ragion di Stato, de 1635 (Cf. CROCE, 1946, p. 75). Rodolfo De Mattei, porém, acertadamente mostra que o Della Ragion di Stato et della prudenza politica (1623), de Federico Bonaventura, já remete a Della Casa (Cf. DE MATTEI, 1979, p. 10).

${ }^{3}$ Nesse sentido, Quentin Skinner parece ter razão ao afirmar que "o mais claro indício de que uma sociedade tenha ingressado na posse consciente de um novo conceito, suponho eu, está na geração de um novo vocabulário, em termos do qual o conceito passa a ser articulado e debatido" (SKINNER, 1996, p. 10).

${ }^{4}$ Faz-se uso aqui de uma citação que Diogo Pires Aurélio (AURÉLIO, 2012, p. 148) retira da Suma Teológica de Tomás: "Aquele que, em caso de necessidade, age à margem das palavras da lei não julga a própria lei, mas julga o caso singular em que verifica não deverem ser observadas as palavras da lei".

${ }^{5}$ Jean Gaudemet (1999) oferece um breve porém eficiente comentário sobre a presença dessa questão nos antigos.

${ }^{6}$ Ainda que nesse momento Itália e França ofereçam as principais contribuições ao debate europeu sobre a razão de Estado, em pouco tempo a questão se espalha por todo o continente. Bom exemplo dessa visibilidade é a menção ao termo na primeira parte de D. Quixote, publicada na Espanha, em 1605 (Cf. CERVANTES, 2010, p. 42). Mais à frente se constata também a presença da ideia de "interesse de Estado" em autores do republicanismo inglês, como James Harrington, que afirma em seu Oceana (1656) ser a razão de Estado nada mais do que o interesse do governante, o interesse do próprio príncipe (Cf. HARRINGTON, 1771, p. 97. Cf. também o capítulo X, dedicado à razão de Estado). No mesmo ano, também Marchamont Nedham dedica atenção ao tema em The
} 
Quase paradoxalmente, contudo, um autor que nunca se referiu diretamente à razão de Estado se torna para os modernos referência quase unânime à questão: Nicolau Maquiavel. O peso desse suposto pioneirismo que se atribui a seu nome é tão grande no período que o debate sobre o novo discurso político passa a se tornar quase indissociável da recepção das obras do filósofo.

A partir de O Príncipe (1532), livro que se espalha rapidamente por todo o continente, "Maquiavel" e "maquiavelismo" se convertem em expressões gradualmente utilizadas como sinônimos, mas de real significado cada vez mais distinto. ${ }^{7}$ Tomando por base passagens polêmicas do livro, como os discursos sobre os usos da crueldade (capítulo VIII), da maldade (XV) e da mentira (XVIII), seus interlocutores da Contrarreforma passam a reforçar uma imagem que pouco a pouco vinha surgindo: a de Nicolau Maquiavel como um pensador demoníaco, e de sua teoria (o "maquiavelismo"), um punhado de escritos do mal. ${ }^{8}$ Toda uma literatura da época, assim, encontra nas passagens do florentino - especialmente nas referidas à conservação do poder de um governo - o ícone maior do que viriam a considerar como a razão do inferno (THUAU, 2000, p. 103).?

Mas apesar do ódio despertado por Maquiavel na Igreja - classificado como "endemoniado, [...] monstro saído do inferno em forma humana, [...] flor fedorenta da bela cidade das flores" (CROCE, 1946, p. 77) -, a nova teoria supostamente trazida por sua obra não podia ser ignorada. Nas palavras de Croce:

Não restava, pois, que começar a trabalhar no que tange àquela ciência; e a domesticá-la, amansá-la, cortar-lhe as pontas afiadas demais, ou buscar conciliá-la [...] com as doutrinas ortodoxas, e sujeitá-la à religião e à moral religiosa (CROCE, 1946, p. 77).

Assim, em oposição à "cruel" lógica política divulgada pelo florentino, é alavancado pelo conservadorismo da Contrarreforma um movimento que viria a ser conhecido como o do antimaquiavelismo. Aqui, mais do que um mero esforço em bradar contra o imoralismo maquiaveliano, é patente a tentativa de adaptar à nova ciência de príncipes às exigências morais e espirituais da fé cristã. Tal como o maquiavelismo, sua corrente antagonista constitui também ela um leque disforme e heterogêneo de textos, nesse caso conectados entre si através dessa "luta pelo bem", encarnada no confronto a Maquiavel. ${ }^{10}$

Excellencie of a Free State (1656), onde estabelece como um erro em política preterir a honestidade em nome da razão de Estado, pois "esses que seguem o outro princípio de "invenção humana", e servem essa deusa italiana, raggione di stato, eles podem viver por enquanto como deuses, mas morrerão como homens, e perecerão como um dos príncipes" (NEDHAM, 1767, p. 143).

7 Claude Lefort se ocupa demoradamente dessa representação coletiva do maquiavelismo, que parece pouco se preocupar em que medida esse pensamento pode ser atribuído ao filósofo. A tal descolamento da teoria de Maquiavel à doutrina atribuída a ele, o francês dá o nome de mito do maquiavelismo. Cf. LEFORT, 1972.

${ }^{8}$ Não por coincidência teve suas obras adicionadas ao Index católico, pelo Concílio de Trento.

9 Também, interessante comentário sobre o assunto, ainda que deva ser lido com cautela, é o artigo La raison d'Etat antimachiavélienne, de Michel Senellart contido em Lazzeri e Reynié (1992).

${ }^{10}$ Joseph Barrère relembra que "o antimaquiavelismo, como o maquiavelismo, carece de unidade; é muito mais um sentimento do que um sistema" (BARRÈRE, 1981, p. 193). 
Principal representante dessa reação, Giovanni Botero é um marco no desenvolvimento da razão de Estado. Um dos principais autores da tratadística, é através de seu Della ragion di Stato (1589) que a noção ganha contornos claros (ainda que delimitados pelo dogmatismo católico) e papel de importância no debate político. ${ }^{11} \mathrm{O}$ pioneirismo do jesuíta, reconhecido por apresentar a primeira tentativa de formalização da ideia, surge logo no primeiro capítulo da obra, que já anuncia uma definição:

Estado é um domínio firme sobre os povos e Razão de Estado é o conhecimento de meios adequados a fundar, conservar e ampliar um Domínio deste gênero. Na verdade, embora, falando em absoluto, ela abranja as três partes supracitadas, parece contudo dizer mais estritamente respeito à conservação do que às outras, e, das outras, mais à ampliação do que à fundação. Isso porque a Razão de Estado pressupõe o Príncipe e o Estado (o primeiro como artífice, o segundo como matéria) e não pressupõe a fundação, que antes a precede completamente, nem a ampliação, que ela precede em parte [...]. E embora tudo o que se faz pelas supracitadas razões se diga fazer-se por Razão de Estado, contudo isto se diz mais daquelas coisas que não podem ser reduzidas a razão vulgar e comum (BOTERO, 1992, p. 76).

Debatendo o lugar da ideia frente à "razão vulgar e comum", o escritor se dedica no decorrer da obra a examinar minuciosamente o assunto, estabelecendo o que é e como opera a razão de Estado, buscando conciliar o aparentemente inconciliável. É no campo dessa contradição - de tentar combater um pensamento sem dele abrir mão - aliás, que parece residir a importância da obra boteriana, representante de uma considerável literatura do período, que se volta com ferocidade contra o que considera a "bárbara maneira de governo [...] que se contrapõe atrevidamente à lei de Deus" (BOTERO, 1606, p. 3). Não à toa, pois, em seu esforço de representar o debate de uma prática política possível ao catolicismo, Botero chegou até mesmo a receber a alcunha de "Maquiavel católico" (BOTERO, 1992, p. IX).

Nas décadas seguintes à publicação do tratado do jesuíta, surgem incontáveis textos, produzidos por um variado leque de autores - de católicos a protestantes -, dedicados a redefinir ou enriquecer a noção de razão de Estado esboçada por ele. Atrelados ou não ao antimaquiavelismo patente de Botero, esse legado de escritores influenciados por sua obra é responsável por expandir até o século XVII a atenção dedicada ao problema em meio ao debate político europeu.

Dentre esses teóricos, Scipione Ammirato e seu Discorsi sopra Cornelio Tacito (1594) se destacam ao produzir uma definição estritamente ligada ao princípio da derroga. Sem romper com o dogmatismo católico que condenava Maquiavel, Ammirato retorna ao tacitismo para justificar ações que, necessárias ao bem comum, podem legitimamente descumprir leis instituídas pelos homens;

\footnotetext{
${ }^{11}$ Maurizio Viroli se refere a esse momento como "uma passagem essencial na história do linguajar político". Cf. o artigo Il significato storico della nascita del concetto di ragion di Stato, em BALDINI, 1995, p. 79.
} 
afinal, o objetivo visado é condizente com o escopo final das leis de Deus. Segundo o autor:

\begin{abstract}
Concluímos, pois, razão de estado ser uma contravenção de razão ordinária em respeito de razão maior e mais universal, ou para ser realmente, digamos, melhor compreendida, razão de estado ser uma coisa oposta ao privilégio. Que se o privilégio corrige a lei ordinária em benefício de alguém; onde se pode dizer que o privilégio é a transposição de razão civil em benefício de particulares. Assim a razão de estado corrige a lei ordinária em benefício de muitos, tal que se poderia propriamente chamar transposição de lei ordinária em benefício de muitos [...] (AMMIRATO, 1599, p. 213).
\end{abstract}

Discutindo, assim, a natureza e a legitimidade da derroga realizada pelo príncipe, Ammirato produz uma distinção implícita entre duas razões de Estado: a má, afeita à tirania, age em vista do interesse de particulares; a boa, por sua vez, o faz apenas voltada ao bem comum. Segundo Viroli, "a definição de razão de Estado em termos de derroga ajuda a distinguir entre a boa e a má razão de Estado" (VIROLLI, 1992, p. 273). E é partir desse pressuposto que o conceito será pensado na França do século XVII.

\title{
2 RazÃo de Estado na França do séc. XVII
}

Enquanto no início dos Seicentos a Itália ainda sentia os efeitos do Concílio de Trento, do outro lado dos Alpes o cenário era um tanto diferente. Em meio a um longo conflito entre católicos e protestantes - com a ausência, portanto, de uma instituição religiosa dominante -, o Estado francês se via em um gradual processo de fortalecimento do poder da monarquia. Mas esse movimento não era recente.

Marco da passagem do domínio feudal ao absolutismo, com a retirada gradual do poder das mãos dos nobres, transferindo-o para o Estado, Luís XI ainda no século XV - dá continuidade ao irreversível processo de centralização, cuja origem remonta ao final do Medievo. Em medidas como a criação de uma nova infantaria, espinha dorsal do exército real, aos poucos o monarca reduzira os serviços oferecidos pela nobreza ao Estado, dando o pontapé inicial na inversão de poderes que caracterizou os séculos seguintes. ${ }^{12}$ Gabriel Naudé, por exemplo,

${ }^{12}$ O debate contemporâneo sobre a imagem de Luís XI é acirrado. Adrianna E. Bakos, em Images of Kingship in Early Modern France: Louis XI in Political Thought, 1560-1789, organiza um retrato histórico da figura de Luís XI, da época de seu reinado até a Revolução Francesa, admitindo que até os dias de hoje a imagem predominante do legado do monarca é a de tirano e déspota. Imediatamente na introdução de seu livro, a autora determina que o rei: "[...] vive no imaginário histórico principalmente como vilão, cruel e astuto [...]. Historiadores modernos de fato tentaram oferecer um saldo mais equilibrado, de um homem complicado governando em tempos difíceis, mas a famosa reputação negativa de Luís XI persiste, apesar desses esforços." (BAKOS, 1997, p. 1). Para Bakos, Luís XI, importante agente na derrocada das velhas estruturas feudais, tem hoje sua própria imagem relacionada a essa pejorativa alcunha principalmente em função das ideias burguesas de liberdade e democracia a nós legadas pela revolução de 1789 , ideias que não poderiam considerar o legado político do monarca como o de um estadista exemplar. Em contrapartida, Jacques Heers, na obra Louis XI, parece tentar oferecer o "saldo mais equilibrado" 
considerado um dos principais nomes do maquiavelismo do século XVII ${ }^{13}$, dedicará um livro inteiro em defesa de Luís XI, ${ }^{14}$ a quem atribui a máxima "qui nescit dissimulare nescit regnare". ${ }^{15}$

Com as guerras de religião que passam a assolar o país no século XVI, mágoas passadas ficam em segundo plano para permitir a união da casa real com as famílias nobres, ao redor do catolicismo e contra um inimigo comum: a rica burguesia protestante, que cresce cada vez mais em poder e influência. Grande desfecho dessa disputa se dá com o Massacre da Noite de S. Bartolomeu, em 1572, que com o aval de Carlos IX dizima violentamente a alta cúpula huguenote, matando milhares de pessoas e repelindo a suposta ameaça de tomada do poder por parte dos protestantes.

Aproximadamente um quarto de século após o Massacre, colocando um fim momentâneo às guerras de religião na França, a união do país ocorreria enfim, mesmo que forçada: assinado em 1598 por Henrique IV, o Édito de Nantes selaria o século com a conciliação religiosa em torno do Estado. Nas palavras de Roland Mousnier:

O Édito de Nantes não tinha nada de excepcional. Era uma "paz religiosa" destinada a permitir a vida dos católicos ao lado dos protestantes sob o mesmo Estado [...]. Os protestantes, tal como os católicos, encontraram na "paz religiosa" uma necessidade, mesmo que infortuna. Todos estavam de acordo ao considerar que a "divisão religiosa" era inadmissível. "A diferença religiosa desfigura o Estado" (MOUSNIER, 1964, p. 127-128).

Embora de maneiras distintas, comentadores como Friedrich Meinecke e Etienne Thuau convergem ao observar as tentativas de colocar fim às divisões

\footnotetext{
citado por Bakos, ao concentrar forças na importância do monarca à história da França, negando apelidos (como o de "Rei Aranha") ou caracterizações históricas definitivas. Nas palavras de Heers, Luís XI, ao marcar o rompimento das estruturas medievais e o início da modernidade no Estado francês, seria, na França, "um dos primeiros heróis dessa "modernidade", a qual o levou a receber, mais do que outros, a atenção de autores ansiosos em anunciar a ruptura entre os príncipes presos a um ideal "cavalheiresco" mas ruins politicamente, e os mais realistas, para os quais, a serviço de seu próprio destino e o do Estado (um e outro muitas vezes confundidos), tudo era possível, desejável e, antecipadamente, justificável.” (HEERS, 2003, p. 353). Apesar de Heers defender que Luís XI tenha sido "em suma um precursor, capaz de governar de outra forma, de sacudir as tradições e renovar as regras do jogo" (2003, p. 353), Bakos não deixa de estar certa.

${ }^{13}$ Cf. Senellart, 1992, p. 28-29. Friedrich Meinecke vai no mesmo sentido, ao afirmar que a principal obra de Naudé, Considérations Politiques sur les coups d'État (1639) "no século XVII se tornou o mais famoso manual de estadismo representante da ordem maquiaveliana." (MEINECKE, 1957, p. 197). Uma longa crítica a essa tese é realizada em GONÇALVES, 2015.

${ }^{14}$ Em Addition à l'Histoire de Louis XI (1630), Naudé se propõe a "adicionar verdades" à história do monarca, "fazendo justiça" ao legado do rei. Ainda na dedicatória da obra, endereçada ao secretário de Estado Etienne Pellault, Luís XI é intitulado por Naudé como "Rei Luís, o Justo", elogiado pelo autor como "fiel" e "íntegro". Em um texto posterior de Naudé (Considérations Politiques), o monarca será definido como "o mais sábio e distinto" dos reis franceses.

15 "Quem não sabe dissimular não sabe governar". Apesar do que diz Gabriel Naudé, é difícil determinar com clareza a autoria dessa sentença. Em Politicorum libri sex (1589), o humanista Justo Lípsio atribui a origem da expressão a Sigismundo de Luxemburgo ou a Frederico III. Autores como Jean Bodin e Giovanni Botero também têm suas versões sobre a origem da frase (Cf. LÍPSIO, 2012, p. 461, nota 371). Adrianna Bakos, por sua vez, apresenta ainda outras origens ao termo (Cf. BAKOS, 1997, p. 123, nota 5).
} 
internas na França em torno de uma estrutura comum, o Estado ${ }^{16}$. Ainda que frágil e de resultados duvidosos, a referida ação de Henrique IV antecipa um novo estilo de relação entre o papel do governante e os interesses estatais, que viriam a encontrar grande espaço na primeira metade do século XVII.

Hubert Méthivier denomina "século de Luís XIII" o período entre 1598 e 1661, "exuberante e [...] barroco por seus excessos e seus contrastes" (MÉTHIVIER, 1967, p. 5), como um prolongamento do "longo século XVI", em oposição à parte seguinte do séc. XVII, pautada pela figura de Luís XIV. Segundo o historiador, o momento histórico que vai de Henrique IV a Mazarin não se resume apenas a Luís XIII, mas marca uma época conturbada e repleta de crises, pautada essencialmente por uma França sob forte influência barroca, na cultura, na sociedade, e principalmente na política. ${ }^{17}$

Braço direito de Luís XIII, Richelieu se torna no período o símbolo maior desse movimento do pensamento político na França. Nas palavras de Julien Freund (1975, p. 142): "a política se emancipa da esfera religiosa sob a égide de um príncipe da Igreja, o cardeal de Richelieu”. Dando continuidade ao processo de organização e centralização da estrutura estatal do país, o cardeal e seu governo se tornam pauta fundamental para os autores do período, que não perdem a oportunidade de traçar paralelos (sejam positivos ou negativos) entre as rédeas da monarquia francesa e a nova ideia onipresente nos debates sobre o poder: $\mathrm{O}$ maquiavelismo.

Do precursor Discours sur les moyens de bien gouverner (1576), o "AntiMachiavel' de Innocent Gentillet, ao De l'interest des Princes et Estats de la Chrestienté (1638) de Henri de Rohan, tratados franceses críticos ou elogiosos (respectivamente) à nova ideia prosperam na França da época, em especial durante o governo de Luís XIII e seu ministro. Essa profusão de textos, tão intimamente ligada ao conturbado período, despertou nos séculos seguintes o interesse dos estudiosos do pensamento político.

\section{ACERCA DOS ESTUDOS SOBRE A RAZÃO DE ESTADO}

A quantidade e a variedade dos estudos existentes sobre a razão de Estado ajudam a dimensionar a amplitude dessa noção multifacetada. ${ }^{18}$

\footnotetext{
${ }^{16}$ Quanto ao primeiro, cf. MEINECKE, 1957, p. 146-162. Já quanto ao francês, ver especialmente o primeiro capítulo: THUAU, 2000, p. 13-32.

${ }_{17}$ Ver especialmente o sintético primeiro capítulo, denominado Aspects originaux du "siècle de Louis XIII" (MÉTHIVIER, 1967, p. 5-20).

${ }^{18}$ Sobre a dificuldade em se reunir as pesquisas sobre o assunto, que se espalham dentro e fora da Europa por diversas áreas (da História ao Direito, passando pela Filosofia e Ciência Política), vale menção ao rigoroso trabalho efetuado por Enzo Baldini (1999), que de forma precisa - mas sem relevar a complexidade do problema -, reuniu um rico panorama das diferentes frentes de estudo que abordam a questão. Apesar de limitado pelo ano de publicação, constitui-se ainda hoje como um punto di riferimento à produção européia sobre a razão de Estado Especial menção ao sucinto porém completo artigo Le ricerche sulla ragione di Stato: situazione e prospettive, contido no volume.
} 
Pode-se localizar como primeira investigação de referência à questão a realizada por Friedrich Meinecke, em Die Idee der Staatsräson in der neueren Geschichte (1924). Segundo o historiador alemão, apesar de traços esparsos da ideia serem passíveis de localização em momentos pontuais da antiguidade ou da Idade Média, é apenas em Maquiavel que ela ganha sua primeira sistematização. Partindo dessa premissa, a obra passa a comentar a recepção dada ao florentino através dos séculos seguintes na França, Itália e Alemanha. Vinculando indissociavelmente a razão de Estado com uma certa concepção da teoria do filósofo, Meinecke não tem pudor em afirmar o que considera "a real origem espiritual do Maquiavelismo: a doutrina infame de que, segundo a conduta comum, mesmo métodos indecorosos são justificados, quando é uma questão de vencer ou manter o poder, o que é necessário ao Estado" (MEINECKE, 1957, p. 36).

A associação desta ideia com o chamado "maquiavelismo" - termo que englobaria uma espécie de pensamento geral do filósofo -, que ganha especial força no final do século XVI, é reavivada tardiamente por Meinecke. ${ }^{19}$

Apesar de o florentino nunca ter utilizado a expressão (razão de Estado), o historiador alemão vai ainda além, ao concluir que ele "por toda sua vida esteve limitado por um propósito supremo definido para o Estado. E, da mesma forma, toda sua forma política de pensar é nada mais que um processo contínuo de pensar sobre a razão de Estado" (MEINECKE, 1957, p. 29).

Ainda na mesma década de Meinecke, Benedetto Croce vai ao encontro do pressuposto dado pelo historiador alemão à fundamentação primeira do conceito. Em seu Storia dell'età barocca in Italia (1929), Maquiavel é apontado como símbolo da nova ciência política trazida à luz no século da Contrarreforma: a razão de Estado. Apesar de apresentar um comentário articulado sobre as leituras barrocas acerca do florentino, Croce não abre mão de considerar maquiavelismo, Maquiavel e razão de Estado como quase sinônimos. ${ }^{20}$

Presente, mas ainda pouco comentada, poucos são os estudos sobre a questão até o final da Segunda Guerra. ${ }^{21} \mathrm{~A}$ partir da segunda metade do século $\mathrm{XX}$, porém, tornam a surgir novas investigações sobre a tratadística, enriquecendo as reconstruções daquele momento histórico. Estudos como o rico livro de Etienne Thuau (2000) dão força a esse recomeço, que começa a perceber - se ainda não uma pluralidade - uma dualidade de visões, resumidas a favoráveis ou opostas, no debate da razão de Estado.

Luigi Firpo e seus trabalhos sobre o pensamento político na Contrarreforma italiana apresentam um novo olhar ao problema, trazendo a importância do antimaquiavelismo católico à cena. ${ }^{22}$ Mais do que mera contraposição às ideias atribuídas aos escritos de Maquiavel, os tratados antimaquiavelistas desenvolviam

19 Observação pertinente, que demonstra essa identificação da razão de Estado com o maquiavelismo por parte de Meinecke, é o título da tradução inglesa de 1957 ao Die Idee der Staatsräson, a saber, Machiavellism: the Doctrine of Raison d'Etat and its Place in Modern History.

${ }^{20}$ Cf. especialmente o capítulo II: Teorie della morale e della politica. La "Ragion di Stato".

${ }^{21}$ Desse período é digno de atenção um ensaio de Norberto Bobbio, que esboça uma aproximação do problema político com o Direito (BOBBIO, 1939).

${ }^{22}$ Dentre os inúmeros comentários de Firpo acerca do assunto, ver FIRPO, 1969. 
uma razão de Estado própria, ainda que com evidentes fraturas. Através de extensa investigação detida em autores como Giovanni Botero, Firpo não apenas reconstrói um momento importante de recusa ao maquiavelismo na Itália, mas também funda uma tradição de pesquisa à questão, que permanece viva até hoje em centros de estudo pelo país.

Auxiliando a aprofundar o entendimento sobre os textos renascentistas relativos à questão, as pesquisas de Rodolfo de Mattei oferecem um amplo panorama do maquiavelismo na recepção à obra do florentino, sem ignorar os problemas de leitura e o contexto que envolve esse extenso leque de autores. ${ }^{23}$ Mais do que um mero apanhado histórico de nomes, obras e datas, o trabalho realizado por De Mattei compõem uma satisfatória busca por princípios comuns que possibilitem conectar esse imbróglio teórico. Também é dele boa parte do mérito de identificar o conceito de prudência como motor da razão de Estado, tese que ganhará força nas décadas seguintes à sua publicação.

Mas é somente alguns anos após o rico debate organizado por Roman Schnur (1975), que foi possível observar um acentuado crescimento no número de relevantes publicações sobre a problemática da razão de Estado; que viriam a atingir seu auge na Europa da década de 90.

Na Alemanha, Michael Stolleis desempenha a principal contribuição à questão. Ainda que sem trazer grande profundidade ou algum fator inédito à tona, o texto de Stolleis ajuda a enriquecer a discussão sobre o problema ao aproximála do direito, especialmente a partir de uma releitura dos comentários de Meinecke (1990) ao maquiavelismo.

É na França, porém, que se encontra a maior e mais reconhecida profusão de estudos recentes acerca da razão de Estado. Publicados no país, ricos compêndios sobre o assunto - reunindo competentes pesquisadores - marcam no final do século XX um breve apogeu de estudos sobre a temática. Obras como as organizadas por Christian Lazzeri e Dominique Reynié (1992), bem como o volume produzido por Yves Zarka (1994, p. 167), aquecem a discussão, ao trazer ao cenário novas possibilidades de leitura. Parecem pecar, porém, na abordagem que propõem sobre o tema, presente em boa parte dos comentários franceses desse momento. Baseando suas leituras em uma espécie de "vocabulário racionalista", um ponto comum nesses estudos é a tentativa de traduzir escritores da época em uma ou mais lógicas racionalizantes. Reynié (1992, p. 11), por exemplo, retorna à "tradição estatizante" para mostrar que a "razão de Estado é também "racionalismo" de Estado", enquanto Zarka (1994, p. 167), por sua vez, vê em teorias como a de Gabriel Naudé a "construção de uma racionalidade puramente política da ação". Ainda que ofereçam imagens que num primeiro momento auxiliem a situar o movimento que guia a evolução das ideias da época, essas leituras encontram aí seu limite, não conseguindo ir além do esboço de uma construção abstrata que pouco esclarece os meandros do problema. Mas é claro que há exceções.

${ }^{23}$ Cf. especialmente De MATTERI, 1969 e 1979. 
Em alguma medida pautados pela influência da obra foucaultiana, merecem destaque os trabalhos de Michel Senellart (1989; 1995). ${ }^{24}$ Com estudos que se propõem a reconstruir em detalhes o percurso teórico através do qual passam o maquiavelismo e a razão de Estado, o francês chega inclusive a se deter em autores como Arnoldo Clapmario, Gabriel Naudé e Justo Lípsio, com úteis conclusões sobre a obra de cada um. Entretanto, um erro visível em outros comentadores franceses, e que também Senellart parece cometer, é a insistência de se tentar ler escritores da razão de Estado através de noções que não aquelas utilizadas pelos próprios sujeitos. Tentativas de reconstruir textos como o de Naudé partindo de ideias que o autor pouco menciona ou não desenvolve claramente, como segredo ou necessidade, parecem fadadas ao engano por não dialogarem com o próprio texto lido, não extraírem da fonte original o argumento que buscam traduzir. Tal método de investigação produz respostas que se creem como esclarecedoras - e que sob determinada ótica até ajudam em certa medida a delimitar a questão -, mas que ao ignorar conceitos centrais de suporte à obra acabam resultando no anacrônico esforço de espremer sob poucas noções uma grande variedade de autores de um mesmo período.

Na Itália, por sua vez, parece se destacar uma maneira ligeiramente diversa de leitura dos escritores modernos da razão de Estado. Em muito inspirados por uma tradição já antiga de estudo à questão, formada por autores como Firpo e De Mattei, os trabalhos que surgem na década de 90 apresentam um caráter próprio, com ao menos duas marcas essenciais. Primeiramente, pode-se observar um aguçado interesse em reconstruir o debate a partir do contexto de cada obra. Mais que meramente descrever uma historiografia das ideias ali presentes, é patente a intenção desses pesquisadores em encontrar um fio teórico que ajude a traçar um percurso argumentativo que tenha conduzido àquela teoria. Bom exemplo são os trabalhos de Enzo Baldini, organizador de diversos volumes voltados ao registro de debates sobre autores e comentadores da razão de Estado (1992, 1995, 1999). ${ }^{25}$ Pupilo de Luigi Firpo, a continuação dada por Baldini aos estudos firpianos sobre Giovanni Botero compõem referência obrigatória acerca do antimaquiavelismo italiano e o papel da Igreja nesse debate. Maurizio Viroli (1992), com sua controversa teoria sobre a linguagem política moderna, é outro exemplo desse esforço. ${ }^{26}$ Como segunda característica das recentes investigações italianas ao tema se percebe a atenção especial dedicada ao conceito de prudência dentro da referida tratadística. Novamente com o apoio de estudos anteriores, autores como Gianfranco Borrelli e Vittorio Dini focam suas atenções na determinante importância dessa noção para boa parte dos textos do período. ${ }^{27}$

\footnotetext{
${ }^{24}$ Senellart também possui textos sobre a referida temática nos volumes mencionados logo antes, organizados por Zarka, Lazzeri e Reynié.

25 Baldini parece ser a melhor referência presente para se mapear os escritos modernos da razão de Estado na Itália e na França, com especial atenção à primeira.

${ }^{26}$ Sobre a obra de Viroli é difícil não concordar com Vittorio Dini (2000, p. 55), segundo o qual ela parece se fechar em "um retorno às teses da razão de Estado como plena e mera autonomização da política frente à esfera da religião".

${ }^{27}$ Boa amostra dessas publicações é o artigo de Borrelli (1992) sobre a articulação entre as noções de sabedoria, prudência e obediência na obra de Botero. Também dele, menção especial ao belíssimo Ragion di Stato. L'arte italiana della prudenza politica (1994). Dini, ainda que pouco
} 
Recentemente, uma nova parcela de comentários sobre a razão de Estado tem surgido, inclusive em língua portuguesa. António Bento (2012a, 2012b) é um representante desse recente interesse pela temática, com tentativas de aproximar a questão a problemas da democracia contemporânea. Parece esbarrar, entretanto, na limitante concepção de traduzir o período em polos maquiavelistas, o que sem dúvida não mais é suficiente para se analisar hoje em dia o referido debate. Também autor de publicação recente, Diogo Pires Aurélio (2012) oferece um útil comentário ao pensamento do florentino, contudo também sem conseguir enxergar a questão desatrelada de Maquiavel. No Brasil, se destaca o trabalho de Roberto Romano, que tem buscado contemplar o estudo da razão de Estado moderna sem abrir mão de pensar a política do tempo presente ${ }^{28}$.

Apesar, porém, do grande horizonte aberto nas últimas décadas pelas pesquisas acerca da razão de Estado, a dificuldade em delinear em termos homogêneos o conceito que a envolve, assim como os autores que a desenvolvem, permanece.

\section{REFERÊNCIAS}

AMMIRATO, Scipione. Discorsi del Signor Scipione Ammirato sopra Cornelo Tacito. Vinezia: Filippo Giunti, 1599.

AURÉLIO, Diogo. Maquiavel e herdeiros. Lisboa: Círculo de Leitores, 2012.

BAKOS, Adrianna. Images of kingship in early modern France: Louis XI in political thought, 1560-1789. New York: Routledge, 1997.

BALDINI, A. Botero e la 'ragion di Stato'. Firenze: Olschki, 1992. Aristotelismo político e ragion di Stato. Firenze: Olschki, 1995. - La ragion di Stato dopo Meinecke e Croce. Dibattito su recenti pubbicazioni. Genova: Name, 1999.

BARRÈRE, Joseph. L'humanisme et la politique dans le discours de la servitude volontarie. Genève-Paris: Slatkine, 1981.

BENTO, António. Maquiavel e o maquiavelismo. Coimbra: Almedina, 2012a.

Razão de Estado e democracia. Coimbra: Almedina, 2012b.

BOBBIO, Norberto. L'interpretazione delle leggi e la ragion di Stato, In: Scritti giuridici in onore di Santi Romano. Padova: CEDAM, 1939.

BORRELLI, Gianfranco. Sapienza, prudenza e obbedienza nel paradigma conservativo di Botero, In: BALDINI, A. Botero e la 'Ragion di Stato'. Firenze: Olschki, 1992.

preocupado com determinados autores, desenvolve valiosa investigação sobre as transformações sofridas pela ideia de prudência na modernidade (DINI; STABILE, 1983 e DINI, 2000).

28 Apesar de vasta, a produção de Roberto Romano sobre a razão de Estado pode ser bem sintetizada no seu título mais recente, que traz uma coletânea de textos e artigos do autor (ROMANO, 2014). 
BORRELLI, Gianfranco. Ragion di Stato. L'arte italiana della prudenza politica. Napoli: Istituto Italiano per gli Studi Filosofici, 1994.

BOTERO, Giovanni. Della ragion di Stato. Venezia, 1606.

. Da razão de Estado. Raffaella Longobardi Ralha (trad.). Coimbra: Instituto Nacional de Investigação Científica, 1992.

CERVANTES, Miguel de. O engenhoso fidalgo D. Quixote da Mancha: volume I. José Luis Sánches e Carlos Nougué (trad.). São Paulo: Abril Coleções, 2010.

CROCE, Benedetto. Storia dell'età barocca in Italia. Bari: Laterza, 1946.

DE MATTEI, Rodolfo. Il problema della "ragion di Stato" nell'età della Controriforma. Milano-Napoli: Ricciardi, 1979.

DINI, Vittorio.; STABILE, Giampiero. Saggezza e prudenza. Studi per la ricostruzione di un'antropologia in prima età moderna. Napoli: Liguori, 1983.

DINI, Vittorio. Il governo della prudenza. Virtù dei privati e disciplina dei custodi. Milano: Franco Angeli, 2000.

FIRPO, Luigi. Le origini dell'anti-machiavellismo. Il Pensiero Politico, ano II, n. 3, 1969, p. 337-367.

FREUND, Julian. La situation exceptionelle comme justification de la raison d'Etat chez Gabriel Naudé, In: SCHNUR, Roman (dir.) Staatsräson, Studien zur Geschichte eines politischen Begriffs. Berlin: Dunker \& Humblot, 1975.

GAUDEMET, Jean. Utilitas publica. In: LAZZERI, Christian.; REYNIÉ, Dominique (eds.). Politiques de l'intérêt. Paris: PUF, 1999.

GONÇALVES, Eugênio. Prudência e razão de Estado na obra de Gabriel Naudé. 2015. Dissertação (Mestrado em Filosofia) - Faculdade de Filosofia, Letras e Ciências Humanas, Universidade de São Paulo, São Paulo, 2015.

HARRINGTON, James. The Oceana and other works of James Harrington. London: Becket and Cadell, 1771.

HEERS, Jacques. Louis XI. Paris: Perrin, 2003.

LAZZERI, Christian.; REYNIÉ, Dominique La raison d'Etat: politique et rationalité. Paris: PUF, 1992.

LEFORT, Claude. Le travail de l'oeuvre Machiavel. Paris: Gallimard, 1972.

LIPSIO,Giusto. Opere Politiche. Torino: Nino Aragno Editore, 2012.

MEINECKE, Friedrich. Machiavellism: the doctrine of raison d'Etat and its place in modern history. Douglas Scott (trad.). London: Routledge and Kegan Paul, 1957. Staat und Staaträson in der frühen Neuzeit: Studien zur Geschichte dês öffentlichen Rechts. Frankfurt: Suhrkamp, 1990.

MÉTHIVIER, Hubert. Le siècle de Louis XIII. Paris: PUF, 1967.

MOUSNIER, Roland. L'assassinat d'Henri IV. Paris: Gallimard, 1964. 
NEDHAM, Marchamont. The excellencie of a Free-State. London: A. Millar and T. Cadell, 1767.

REYNIÉ, Dominique. Les pouvoir de la raison d'Etat, Paris: PUF, 1992.

ROMANO, Roberto. Razão de Estado e outros estados da razão. São Paulo: Perspectiva, 2014.

SCHNUR, Roman (ed.). Staatsräson. Studien zur Geschichte eines politischen Begriffs. Berlin: Duncker \& Humblot, 1975.

SENELLART, Michel. Machiavélisme et raison d'Etat. Paris: PUF, 1989

La raison d'Etat antimachiavélienne. In: Christian, LAZZERI; D. REYNIÉ, Dominique (ed.). La raison d'état: politique et rationalité. Paris, PUF, 1992.

Les arts de gouverner. Du regimen médiéval au concept de gouvernement. Paris: Éditions du Seuil, 1995.

THUAU, Éttiene. Raison d'Etat et pensée politique à l'epoque de Richelieu. Paris: Albin Michel, 2000.

VIROLI, Maurizio. From politics to reason of State: the acquisition and transformation of the language of politics, 1250-1600. New York: Cambridge Press, 1992.

ZARKA, Yves (ed.). Raison et déraison d'État. Paris: PUF, 1994.

Recebido em: 22-08-2019

Aceito para publicação em: 12-12-19 